\title{
Drugie stanowisko Trichoglossum hirsutum (Ascomycota) na Pomorzu Zachodnim (Polska północno-zachodnia)
}

Rodzaj Trichoglossum Boud. (włosojęzyk), należący do rodziny Geoglossaceae Corda, obecnie obejmuje 19 gatunków (EKANAYAKA i in. 2017). W Polsce jest reprezentowany tylko przez Trichoglossum hirsutum (Pers.) Boud. (syn. Geoglossum hirsutum Pers.) włosojęzyk szorstki i T. walteri (Berk.) E.J. Durand, przy czym oba te taksony są rzadko odnotowywane na tym obszarze (CHMIEL 2006; KuJAwA 2020). Różnią się one głównie budową zarodników, przede wszystkim liczbą występujących w nich przegród. T. hirsutum charakteryzuje się brązowymi zarodnikami, o 13-17 przegrodach, a T. walteri jasnobrązowymi o mniejszej liczbie, 0-7 przegród (EKAnAYAKa i in. 2017). Ponadto owocniki pierwszego z nich mogą osiągać większe rozmiary, do $10 \mathrm{~cm}$ wysokości, podczas gdy drugiego zwykle nie przekraczają $7 \mathrm{~cm}$ (HANSEN \& KNUDSEN 2000).

Trichoglossum hirsutum swym zasięgiem obejmuje Europę, Afrykę, Amerykę Północną i Środkową, Azję, Australię i Nową Zelandię (np. MaAs Geesteranus 1965; DouAnlaMeli \& Langer 2005; Beug i in. 2014; AnOnymous 2020; FARr i in. 2020; Hodge \& GrufF 2020). Mimo tak szerokiego rozprzestrzenienia włosojęzyk szorstki w wielu krajach jest

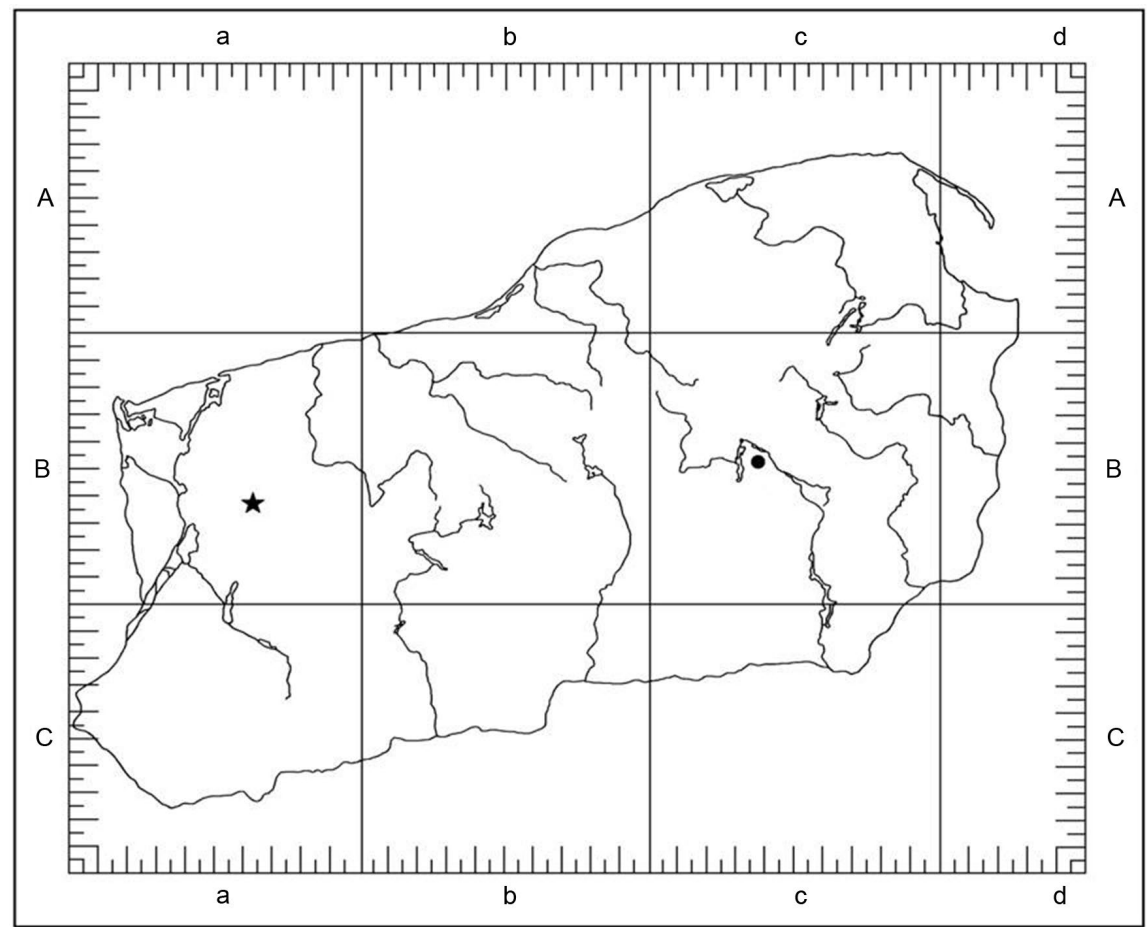

Ryc. 1. Rozmieszczenie Trichoglossum hirsutum na Pomorzu Zachodnim w siatce kwadratów ATPOL: $10 \times 10 \mathrm{~km}$ (WoJEWODA 2000). Czarny punkt - Park Narodowy Bory Tucholskie; czarna gwiazdka - rezerwat przyrody Wrzosiec

Fig. 1. Distribution of Trichoglossum hirsutum in Western Pomerania in the ATPOL grid square: $10 \times 10 \mathrm{~km}(\mathrm{Wo}-$ JEWODA 2000). Black points - the National Park Bory Tucholskie; black star - the Wrzosiec nature reserve 

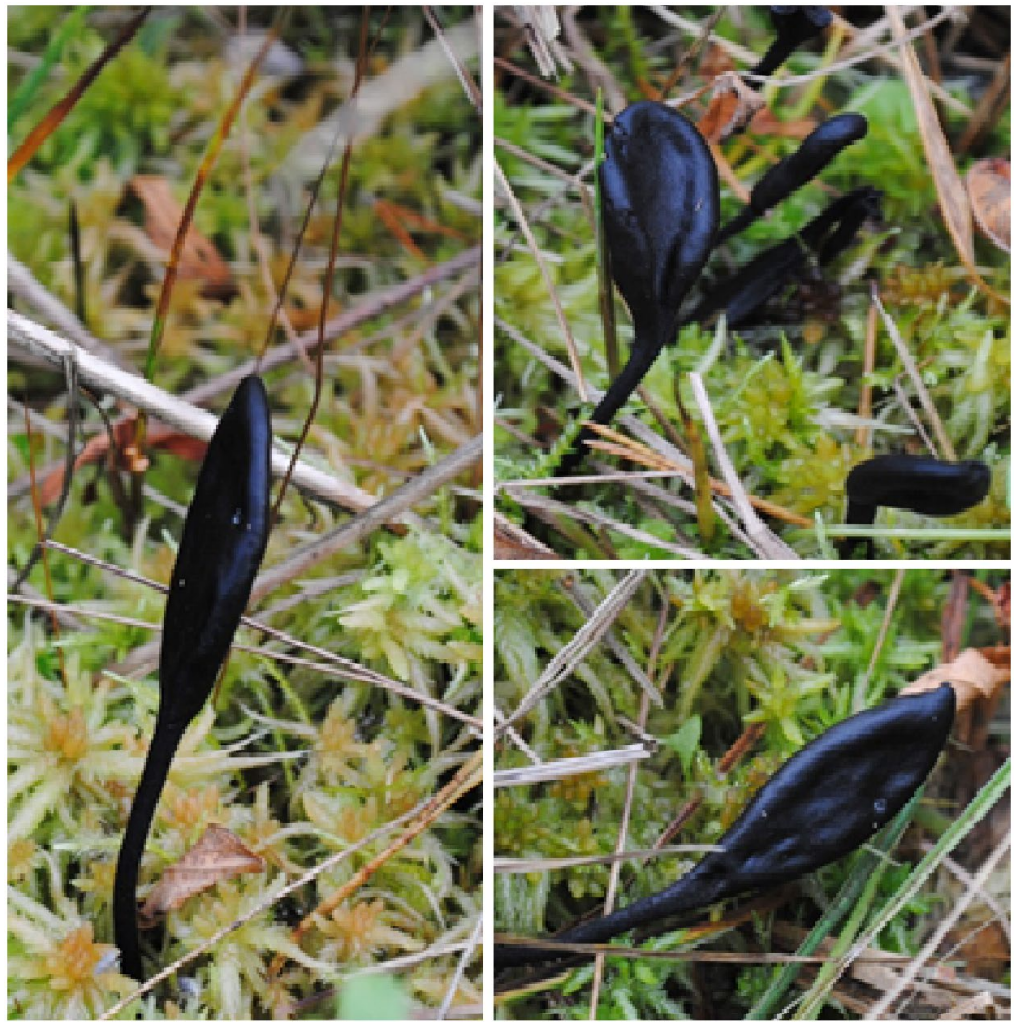

Ryc. 2. Owocniki Trichoglossum hirsutum w rezerwacie przyrody Wrzosiec (06.10.2014; fot. M. Stasińska)

Fig. 2. Trichoglossum hirsutum ascomata in the Wrzosiec nature reserve (06.10.2014; photo by M. Stasińska)

rzadko notowany i uznawany za zagrożony. Znajduje się na czerwonych listach grzybów i klasyfikowany jest do różnych kategorii zagrożeń, np. wymierające (E, EN) w Polsce (Wojewoda \& Ławrynowicz 2006), Czechach (Holec \& Beran 2006) i na Słowacji (LizoŇ 2001), narażone (VU) w Austrii (DÄMON \& KRISAI-GREILHUBER 2016) i bliskie zagrożenia (NT) w Szwajcarii (SENN-IRLET i in. 2007). W Polsce objęty jest częściową ochroną (ROZPORZĄDZENIE 2014).

Nowe stanowisko Trichoglossum hirsutum odnotowano w rezerwacie torfowiskowym Wrzosiec znajdującym się na obszarze ochrony siedlisk Natura 2000 Ostoja Goleniowska (PLH 320013) i położonym około 1,5 km na północ od miejscowości Krzywice, w Nadleśnictwie Nowogard (oddz. 312 i), ATPOL: Ba-6622 (Ryc. 1). Owocniki T. hirsutum (Ryc. 2) stwierdzono 6 października 2014 r., w południowo-zachodniej części torfowiska wysokiego $\left(53^{\circ} 36^{\prime} 57,1^{\prime \prime} \mathrm{N}, 1^{\circ} 57^{\prime} 41,5^{\prime \prime} \mathrm{E}\right)$, w płatach przekształconych zbiorowisk roślinnych o nieokreślonej przynależności syntaksonomicznej, zlokalizowanych nieopodal boru bagiennego Vaccinio uliginosi-Pinetum Kleist 1929. Rosły one na martwych szczatkach roślin, kępach Molinia caerulea i wśród torfowców (Sphagnum spp.), w sąsiedztwie Hydrocotyle vulgaris, Drosera rotundifolia, Lysimachia vulgaris, Phragmites australis, Comarum palustre i turzyc (Carex spp.). Miejsca występowania T. hirsutum były silnie uwodnione. 
Na powierzchni około $50 \mathrm{~m}^{2}$ odnotowano 62 owocniki, które rosły w rozproszeniu, pojedynczo lub w małych grupach po 3-5 (leg. Z. Sotek, I. Pilarczyk, M. Stasińska, det. M. Stasińska; SZUB-F 959-960).

Trichoglossum hirsutum jest prawdopodobnie grzybem saprotroficznym i odznacza się dość szerokim spektrum siedlisk, w których występuje. Notowany jest na wilgotnych łąkach, pastwiskach, różnego rodzaju torfowiskach i w lasach. Rośnie na wilgotnej glebie, martwych szczątkach roślin i rozkładającym się drewnie, często wśród Sphagnum spp. (np. SENN-IRLET i in. 2007; KUČERA $i$ in. 2008). W Polsce grzyb ten stwierdzany był w zbiorowiskach roślinnych ze związku Phragmition (GRZESIAK i in. 2017), w lasach liściastych i na ich obrzeżach, pod krzewami (głóg, rokitnik), na ziemi, wśród gnijących liści i mchów, w tym torfowców (RUDNICKA-JEZIERSKA 1969; KuJAwA 2020).

Na Pomorzu Zachodnim włosojęzyk szorstki znany jest z dwóch udokumentowanych stanowisk (Ryc. 1). Pierwsze z nich znajduje się w Parku Narodowym Bory Tucholskie (GRZESIAK i in. 2017), natomiast drugie to stanowisko nowo odkryte, zlokalizowane w rezerwacie Wrzosiec. O występowaniu T. hirsutum na Pomorzu donosił już w XIX w. Homann (1835), ale brak podanej dokładnej lokalizacji stanowisk uniemożliwia ustalenie, czy znajdują się one w obecnych granicach Polski.

W Polsce, Trichoglossum hirsutum jest grzybem rzadko spotykanym; znany jest z około 10 współczesnych (po roku 1970) stanowisk (CHMIEL 2006; KuJAwa 2020). Ze względu na różnorodność siedlisk, w których włosojęzyk szorstki występuje i na dość liczne notowania na terenie sąsiadujących z Polską Niemiec (DÄMMRICH i in. 2020), należy się spodziewać, że przy kolejnych eksploracjach mykologicznych, będzie stwierdzany częściej również w Polsce.

Podziękowania. Dziękujemy Recenzentom za uwagi krytyczne do manuskryptu pracy. Praca została sfinansowana ze środków na badania Instytutu Nauk o Morzu i Środowisku Uniwersytetu Szczecińskiego.

Summary. The second record of Trichoglossum hirsutum (Ascomycota) from Western Pomerania, NW Poland. This paper presents a new locality of Trichoglossum hirsutum (Pers.) Boud. and the current distribution of this fungus in the Western Pomerania region (Fig. 1). A new locality of T. hirsutum was noted in the Wrzosiec Peatland Reserve in the Ostoja Goleniowska Natura 2000 habitat protection area (PLH 320013), $1.5 \mathrm{~km}$ north of Krzywice, in the Nowogard Forest District (division 312i), ATPOL: Ba-6622. The ascomata were found on 6 October 2014, in the south-western part of the raised bog $\left(53^{\circ} 36^{\prime} 57.1^{\prime \prime} \mathrm{N}, 14^{\circ} 57^{\prime} 41.5^{\prime \prime} \mathrm{E}\right)$ in patches of transformed plant communities of an unspecified syntaxonomic rank located near a pine bog forest. T. hirsutum (Fig. 2) grew on dead plant matter, tufts of Molinia caerulea and among Sphagnum spp., near Hydrocotyle vulgaris, Drosera rotundifolia, Lysimachia vulgaris, Phragmites australis, Comarum palustre and Carex spp. The sites of T. hirsutum were highly hydrated. Sixty-two ascocarps were noted over an area of $\sim 50 \mathrm{~m}^{2}$. They grew dispersed separately or in small groups of 3-5 fungi.

\section{LITERATURA}

ANONYMOUS 2020. NZFUNGI - New Zealand fungi (and bacteria). https://www.landcareresearch.co.nz/ resources/data/nzfungi (dostęp: 05.06.2020).

Beug M. W., Bessette A. E. \& Bessette A. R. 2014. Ascomycete Fungi of North America: A Mushroom Reference Guide. s. 502. University of Texas Press, Austin. 
Chmiel M. A. 2006. Checklist of Polish larger Ascomycetes. - W: Z. MireK (red.), Biodiversity of Poland. 8, s. 152. W. Szafer Institute of Botany, Polish Academy of Sciences, Kraków.

Dämmrich F., Gminder A., HardtKe H. J., Karasch P. \& Wehr K. 2020. Datenbank der Pilze Deutschlands, Deutsche Gesellschaft für Mykologie e. V. (DGfM). http://www.pilze-deutschland.de/ (dostęp: 05.06.2020).

DÄmon W. \& KrisaI-Greilhuber I. 2016. Die Pilze Österreichs. Verzeichnis und Rote Liste 2016. Teil: Makromyzeten. s. 610. Österreichische Mykologische Gesellschaft, Wien.

Douanla-Meli C. \& Langer E. 2005. Notes on Discomycetes (Helotiales, Pezizales): new species and new records from Cameroon. - Mycotaxon 92: 223-237.

Ekanayaka A. H., Hyde K. D., Jones E. G., Zhao Q., Elgorban A. M. \& Bahkali A. H. 2017. A new species of Trichoglossum (Geoglossales, Ascomycota) from Thailand. - Phytotaxa 316(2): 161-170.

Farr D. F. \& Rossman A. Y. 2020. Fungal Databases, U.S. National Fungus Collections, ARS, USDA. https://nt.ars-grin.gov/fungaldatabases/ (dostęp: 05.06.2020).

Grzesiak B., Wolski G. J., Salamaga A., Kochanowska M. \& Kochanowski J. 2017. Grzyby makroskopowe Parku Narodowego „Bory Tucholskie”. - Parki Narodowe i Rezerwaty Przyrody 36(1): 5-36.

HANSEn L. \& KnUdSEn H. (red.). 2000. Nordic macromycetes. Ascomycetes. 1, s. 309. Nordsvamp, Copenhagen.

Hodge K. T. \& GRUFF S. C. 2020. Plant pathology herbarium (CUP). http://www.plantpath.cornell.edu/ CUPpages/CUPtype.html (dostęp: 05.06.2020).

HoleC J. \& Beran M. (red.). 2006. Červený seznam hub (makromycetů) České republiky (Red list of fungi (macromycetes) of the Czech Republic). - Př́roda 24: 1-282.

Homann G. G. J. 1835. Flora von Pommern, oder Beschreibung der in Vor- und Hinterpommern sowohl einheimischen als auch unter freiem Himmel leicht fortkommenden Gewächse; nebst Bezeichnung ihres Gebrauches für die Arzenei, Forst- und Landwirtschaft, Gärtnerei, Färberei u.s.w., ihres etwanigen Nutzens oder Schades. Dritter und letzter Band, enthaltend die ein u. zwanzigste bis zu Ende der vier u. zwanzigsten Klasse. 3, s. 453. Druck und Verlag von E. G. Hendeß, Cöslin.

KuČERA V., Lizoñ P. \& KAUtMAnová I. 2008. Geoglossaceous fungi in Slovakia: rare and new taxa for the territory. - Biologia 63(4): 482-486.

KuJawa A. 2020. Grzyby makroskopijne Polski w literaturze mykologicznej. - W: M. SnOwarski, Atlas grzybów Polski, http://www.grzyby.pl/grzyby-makroskopijne-Polski-w-literaturze-mikologicznej.htm (dostęp: 05.06.2020).

LizoŇ P. 2001. Red list of Slovak fungi. - Catathelasma 2: 25-33.

MaAs Geesteranus R. A. 1965. Geoglossaceae of India and Adjacent Countries. - Persoonia 4(1): 19-46.

RoZPORZĄDZENIE Ministra Środowiska z dn. 9 października 2014 r. w sprawie ochrony gatunkowej grzybów. (Dz. U. 2014 r., poz. 1408).

RudNICKA-JEZIERSKA W. 1969. Grzyby wyższe wydm śródlądowych Puszczy Kampinoskiej. - Monographiae Botanicae 30: 3-116.

Senn-Irlet B., Bieri G. \& Egli S. 2007. Rote Liste der gefahrdeten Grosspilze der Schweiz. UmweltVollzug Nr. 0718, s. 92. Hrsg. Bundesamt für Umwelt, Bern, und WSL, Birmensdorf.

Wojewoda W. (red.). 2000. Atlas of the geographical distribution of fungi in Poland. Fascicle 1, s. 61. W. Szafer Institute of Botany, Polish Academy of Sciences, Kraków.

Wojewoda W. \& EaWrynowicz M. 2006. Red list of the macrofungi in Poland. - W: Z. MireK, K. Zarzycki, W. Wojewoda \& Z. Szelą (red.), Red list of plants and fungi in Poland, s. 53-70. W. Szafer Institute of Botany, Polish Academy of Sciences, Kraków. 
MaŁgorZata Stasińska (autor korespondencyjny), Zofia Sotek, Instytut Nauk o Morzu i Środowisku, Uniwersytet Szczeciński, ul. Mickiewicza 16, 70-383 Szczecin, Polska; e-mail: malgorzata.stasinska@usz.edu.pl; zofia.sotek@usz.edu.pl

PAtrycja RadKe, Instytut Biologii, Uniwersytet Szczecinski, ul. Waska 13, 71-415 Szczecin, Polska; e-mail: patrycjaradke7@gmail.com

Wptynęto: 18.07.2020 r.; przyjęto do druku: 09.11.2020 r.

DOI: https://doi.org/10.35535/ffgp-2020-0025

\section{Trichia sordida (Trichiaceae) - nowy dla Polski i Karpat gatunek śluzowca przyśnieżnego znaleziony w Tatrach}

Śluzowce są mało poznaną grupą organizmów grzybopodobnych, należącą do królestwa Amoebozoa (ADL i in. 2019) i obejmującą około 1000 gatunków (RoNIKIER \& HALAMSKI 2018). Charakteryzuje je skomplikowany cykl rozwojowy, którego głównym stadium wegetatywnym jest wielojądrowa mobilna masa protoplazmy nazywana śluźnią (plazmodium) (MARTIN \& Alexopoulus 1969). Po pewnym czasie życia w glebie, śluźnia wypełza na powierzchnię i przechodzi transformację, której efektem jest wytworzenie zarodni wypełnionych masą zarodników (KELLER i in. 2017). Śluzowce są organizmami kosmopolitycznymi (EvERHART \& KeLler 2008). Najczęściej spotykane są w lasach klimatu umiarkowanego, jednak zdolne są do opanowywania różnych środowisk, często o skrajnych warunkach siedliskowych, takich jak pustynie czy strefy na granicy topniejącego śniegu w górach (LiU i in. 2015).

Jedną z grup szczególnie interesujących z ekologicznego i ewolucyjnego punktu widzenia są śluzowce przyśnieżne związane z wąskim spektrum warunków środowiskowych panujących na przedpolu topniejącej zimowej pokrywy śniegu. Śluzowce przyśnieżne występują głównie na obszarach o charakterze górskim, gdzie gruba pokrywa śniegu zalega przez długi okres czasu i stopniowo topnieje wiosną i wczesnym latem. Na obszarze Polski gatunki należące do tej grupy podawane były głównie z Tatr, Gorców oraz - rzadziej - z innych części Beskidów (Drozdowicz 1988; Komorowska \& Drozdowicz 1996; RonikiER i in. 2008; BochyNEK \& DROZDOwicz 2012; JANIK \& RonikiER 2016). W Tatrach odnotowano dotychczas dziesięć gatunków śluzowców przyśnieżnych: Diderma alpinum (Meyl.) Meyl., D. fallax (Rostaf.) E. Sheld., Lamproderma argenteobrunneum A. Ronikier, Lado \& Mar. Mey., L. sauteri Rostaf., Lepidoderma carestianum (Rabenh.) Rostaf., Meriderma carestiae (Ces. \& de Not.) Mar. Mey. \& Poulain, M. echinulatum (Meyl.) Mar. Mey. \& Poulain, M. spinulosporum ad. int., Physarum albescens Ellis ex T. Macbr. oraz Trichia alpina (R. E. Fr.) Meyl. (Drozdowicz 1988, 1995; Komorowska \& Drozdowicz 1996; Ronikier $\mathrm{i}$ in. 2010; JANIK \& RONIKIER 2016).

Rodzaj Trichia skupia gatunki charakteryzujące się jasną barwą zarodników i włośnią mającą postać wolnych nici (sprężyc) ornamentowanych spiralnymi zgrubieniami (wężownicami). Z Polski znanych było 14 gatunków z tego rodzaju (DrozDowicz i in. 2003), z których tylko jeden, Trichia alpina, jest gatunkiem przyśnieżnym (DrozDowicz 1988, 